\title{
The Effect of Direct Acting Antivirals on Portal Hemodynamics in Patients with Post Hepatitis C Cirrhosis: Doppler Study
}

\author{
Amira Shaaban Soliman ${ }^{1 *}$, Fathia El sayed Asal ${ }^{1}$, Sahar Abdel Tawab El yamani ${ }^{1}$, \\ Amr Mohamed Tawfik Elbadry ${ }^{2}$, Nehad Ibrahim Hawash ${ }^{1}$ and Mahmoud Anees Khedr ${ }^{1}$ \\ ${ }^{1}$ Department of Tropical Medicine and Infectious Diseases, Faculty of Medicine, \\ Tanta University, Tanta, Egypt \\ ${ }^{2}$ Department of Radiodiagnosis, Faculty of Medicine, Tanta University, Tanta, Egypt \\ *Corresponding author
}

\section{Keywords \\ HCV, Cirrhosis, Portal hypertension, Doppler, Direct acting antivirals \\ Article Info \\ Accepted: \\ 26 September 2020 \\ Available Online: \\ 10 October 2020}

\section{A B S T R A C T}

Hepatitis $\mathrm{C}$ viral clearance after receiving direct acting drugs had been established that results in reduced morbidity and mortality due to chronic liver disease, however how this affects clinical outcomes in patients with already established cirrhosis and portal hypertension (PH) is still controversial. We aimed to assess the effect of direct acting antivirals on portal hemodynamics by Doppler ultrasound in patients with post hepatitis $\mathrm{C}$ cirrhosis. Fifty patients with post hepatitis C cirrhosis as documented by Ultrasound. All patients received direct acting drugs for 12 weeks except for 2 patients received treatment for 24 weeks. Laboratory tests (liver function tests, complete blood picture, alpha feto protein, renal function tests, serum HBs antigen, Quantitative PCR for HCV RNA, modified Child-Pugh Score, Model for End stage Liver Disease Score (MELD) calculation, Ultrasound examination and Doppler ultrasound for assessment of (portal vein flow velocity (PVV), congestion index (C I), hepatic Arterial pulsatility and resistive indices (HAPI, HARI), and Liver vascular index (LVI) were performed before, at end of therapy and 6 months after the end of treatment for all patients. Twenty six male $(52 \%)$ and 24 females (48 \%) were included, their mean age 57.360, 46 patients were Child A. 47 patients achieved sustained virological response (SVR). Serum albumin, bilirubin, ALT, AST, hemoglobin, white blood cells and alpha feto protein were improved significantly 6 months later. As regard Doppler parameters there was a highly significant increase in Portal vein flow velocity (PVV) and liver vascular index (LVI), and decrease in congestion index (C I) ( P value $<0.001$ ) at end of therapy and 6 months after end of therapy, hepatic artery pulsatility (HAPI) and resistive index (HARI) were significantly decreased at end of therapy $(\mathrm{P}$ value $=0.020,0.008$ respectively) and at 6 months after end of therapy $(\mathrm{P}$ value $=0.011,<0.001$ respectively). Achieving Sustained virologic response by the use of directacting antivirals in HCV related cirrhosis, improve liver blood flow and liver perfusion. 


\section{Introduction}

One of the leading causes of chronic liver disease is hepatitis $\mathrm{C}$ virus (HCV) infection with a highly variable long term impact that range from minimum histological changes to extensive fibrosis and cirrhosis with or without hepatocellular carcinoma (HCC) (1).

Among all countries suffering from $\mathrm{HCV}$ infection Egypt ranks the $5^{\text {th }}$, as up to $15 \%$ of the adult population are seropositive for $\mathrm{HCV}$ infection while more than four million individuals stay viraemic (2). So, viral clearance achievement is critical and is associated with reduced rates of liver failure and liver-related deaths amongst chronic hepatitis $\mathrm{C}(\mathrm{CHC})$ patients (3). In addition, it significantly reduces fibrosis progression rates and even reverses cirrhosis (4). DAAs are molecules that target specific nonstructural proteins of the virus and results in disruption of viral replication and infection. According to their mechanism of action and therapeutic target DAAs were classified into four classes (5).

One of the main complication of chronic liver disease is portal hypertension (PHT), with severe consequences including: bleeding from gastroesophageal varices, portal hypertensive gastropathy, ascites, spontaneous bacterial peritonitis, hepatorenal syndrome, hepatopulmonary/portopulmonary syndromes, and hepatic encephalopathy (6). For the development of esophageal varices and variceal bleeding hepatic venous pressure gradient must raise $\geq 10 \mathrm{mmHg}$. (7)As the direct measurement of portal pressure by measuring hepatic venous pressure gradient is invasive, inconvenient, and clinically impractical (7), Duplex Doppler sonography was validated for; the assessment of the vascular system of the liver, the presence of portal hypertension and its complications in cirrhotic patients. (8)
The aim of our work was to assess the effect of direct acting antivirals on portal hemodynamics by Doppler ultrasound in patients with post hepatitis $\mathrm{C}$ cirrhosis.

\section{Patients and Methods}

This prospective study was carried on 50 patients with post hepatitis $\mathrm{C}$ cirrhosis candidates for treatment with direct acting antiviral agents (DAAs) as defined by the National Treatment Protocol receiving treatment at Tanta University Educational Hospital Unit for Control of Viral Hepatitis with follow up of portal hemodynamics by Doppler ultrasound in Tropical Medicine Department, Tanta University Hospital in three occasions; before treatment with DAAs, at the end of treatment and 6 months after the end of treatment.

Patients were enrolled from February 2018 to July 2018 and they were followed up for 9 months. All patients provided informed written consent and the study was approved by Ethical Committee of Faculty of Medicine, Tanta University (Approval code 31791/10/17). All patients had code numbers to insure their privacy. Documented Consent from ministry of Health, National Committee for Control of Viral Hepatitis was also provided.

\section{Inclusion criteria}

Patients with post hepatitis C cirrhosis. Positive diagnosis of liver cirrhosis $+/$ - portal hypertension by clinical, laboratory tests and ultrasound: (coarse echogenic pattern, surface irregularity, bulky caudate lobe, attenuated hepatic veins), manifestations of PHT (splenomegaly and ascites). $(9,10)$

Patients with hepatitis other than HCV related cirrhosis, hepatocellular carcinoma, patients with previous endoscopic sclerotherapy or 
band ligation of varices, history of surgical shunts (TIPS), patients on beta-blocker and patients with portal vein thrombosis (PVT) were excluded from the study.

Patients included received according to the Egyptian protocol for treatment of chronic $\mathrm{HCV}$ in form of:

-SOF+DCV+RBV (12Weeks) (45 patients)

- SOF+DCV+RBV (24Weeks) (2 patients)

- SOF+DCV +SMV+RBV (12Weeks) (2 patients)

- SOF+DCV (24Weeks) (1 patient)

Patients fulfilling inclusion and exclusion criteria for treatment were subjected to the following

Detailed history taking, through clinical examination, laboratory investigations including: Complete blood, kidney function tests, liver function tests, coagulation profile, serum HBs antigen, serum alpha feto protein, Quantitative PCR for HCV RNA before and after 12 weeks after treatment completion, liver disease staging using The modified Child-Pugh Score, Model for End stage Liver Disease Score (MELD) calculation.

- Radiological imaging:

\section{Abdominal ultrasonography}

All assessments were done by using Toshiba Nemio XG apparatus by using B-mode ultrasound, the patients were fasting at least for 6 hours and the patients were in the supine position to assess: (Liver echogenicity, surface, edge, size), portal vein diameter, attenuation of hepatic veins, size of spleen and presence of ascites.

Triphasic abdominal CT in suspected cases of hepatic focal lesion to Exclude HCC.

\section{Color Doppler ultrasound to evaluate}

Portal vein flow direction, portal vein flow velocity $(\mathrm{PVV})$, congestion index $(\mathrm{C} \mathrm{I})=$ the ratio of portal vein cross-sectional area and portal blood flow velocity), hepatic Arterial pulsatility index (HAPI) = Peak systolic velocity - end diastolic velocity/ mean velocity, Arterial resistive index $(\mathrm{HARI})=$ Peak systolic velocity - end diastolic velocity/peak systolic velocity. Liver vascular index $(\mathrm{LVI})=\mathrm{PVV} / \mathrm{HAPI}$

All Doppler parameters were done by using Toshiba Nemio XG apparatus with a convex probe $3.5 \mathrm{MHz}$ with color Doppler. The patients were fasting at least for 6 hours; the patients were in supine position. Doppler analysis was performed with respiration halted at light inspiration or during quiet respiration. (11)The Doppler gate was placed in the porta-hepatis to measure the relevant portal vein, hepatic artery parameters. Pulsatility and resistive indices were calculated automatically by the machine after the waveform trace of the artery with an angle less than 60 degree between the vessel \& US beam. The Doppler sample volume cursor was positioned in the center of the vessel lumen.. At the beginning, we unified the method of measuring each index by the same observer to avoid interobserver variability. Each index was calculated as the mean of 3 consistent measurements. (12)

Laboratory tests and Doppler parameters were evaluated on three occasions: before treatment, at the end of treatment and 6 months after the end of treatment.

\section{Results and Discussion}

Fifty (50) patients with HCV infection were included in our study with mean ages were $57.360 \pm 9.167$, mean weight was $88.400 \pm$ $9.444 \mathrm{~kg}$, twenty-six males $(52 \%)$ patients 
and 24 females (48\%), mean MELD score $9.04 \pm 2.441$. Forty-six $(92 \%)$ of patients were Child A and $4(8 \%)$ patients were Child B. Only $3(47 \%)$ patients had ascites of mild to moderate degree while 8 patients had lower limb edema..

Forty-six patients (92\%) were treatment Naïve and $4(8 \%)$ patients were treatment experienced (Figure 1).

Forty seven (94\%) of patients achieved sustained virologic response (SVR12).

\section{Laboratory parameters of the study population}

There was a statistically significant decrease of hemoglobin level at the end of treatment and significantly increased 6 months after treatment completion. Also WBC count was significantly increased 6 months after the end of treatment. Except for bilirubin, liver function tests showed significant improvement at end of therapy and six months after treatment, while bilirubin was significantly increased at end of therapy then significantly decreased 6 months after end of treatment. In addition alpha feto protein levels were significantly decreased when compared its level before, at end of therapy and 6 months after end of therapy (Table 1).

\section{Doppler parameters}

Mean of portal vein diameter $1.47 \pm 0.256$ and mean of spleen15.582 \pm 2.566 .

There was significant improvement portal vein velocity, congestion index, hepatic artery resistance index, and liver vascular index at end of therapy and 6 months after end of treatment as there was significant increase in PVV (P-value <0.001) and LVI (P-value $<0.001)$, while there was significant decrease in congestion index (P-value <0.001), HARI
(P-Value 0.008), while hepatic artery pulsatility index showed significant decrease at end of therapy ( $\mathrm{P}$ value 0.011 ) (Table 2 and figure 2,3 ).

There was highly significant positive correlation between PVD and CI before treatment, after the end of treatment and 6 months after the end of treatment (Pvalue<0.001).

There was also significant negative correlation between age and PVV before treatment (P-value 0.007), after the end of treatment (P-value 0.014) and 6 months after the end of treatment (P-value0.05).

There was significant negative correlation between age and LVI before treatment (Pvalue 0.013$)$, after the end of treatment $(\mathrm{P}-$ value 0.05 ).

There was no significant correlation between MELD score and Doppler Parameters in the 3 occasions of our study.

\section{Statistical analysis}

The collected data were organized, tabulated and statistically analyzed using statistical package for social studies (SPSS) version 19. For numerical variable, the mean and standard deviation were calculated. Paired t-test and Differences of mean value between the variables in the three occasions of follow up. Linear Correlation Coefficient by SPSS V20. $P$ value is considered either non- significant if $>0.05$, significant $(\mathrm{S})$ if $<0.05$, or highly significant $(\mathrm{HS})$ if $<0.001$ was calculated.

It is well documented that viral clearance after DAAs treatment decreases mortality and morbidity in patients with chronic liver disease (13), but this effect in patients with established cirrhosis and portal hypertension is still under debate. 
Table.1 Laboratory parameters and MELD score

\begin{tabular}{|c|c|c|c|c|c|c|c|c|c|c|c|}
\hline \multirow[b]{3}{*}{ Before treatment } & \multicolumn{6}{|c|}{ Hemoglobin level (gm / dL) } & \multirow{3}{*}{$\begin{array}{c}\text { COMP. } \\
\text { B-E }\end{array}$} & \multicolumn{2}{|c|}{ Differences } & \multicolumn{2}{|c|}{ Paired Test } \\
\hline & \multicolumn{3}{|c|}{ Range } & \multirow{2}{*}{$\begin{array}{l}\text { Mean } \\
13.164\end{array}$} & \multirow{2}{*}{$\begin{array}{l} \pm \\
\pm\end{array}$} & \multirow{2}{*}{$\begin{array}{c}\text { SD } \\
1.323\end{array}$} & & \multirow{2}{*}{$\begin{array}{c}\text { Mean } \\
1.174\end{array}$} & \multirow{2}{*}{$\begin{array}{c}\text { SD } \\
1.308\end{array}$} & \multirow{2}{*}{$\begin{array}{c}\mathbf{T} \\
6.345\end{array}$} & \multirow{2}{*}{$\begin{array}{l}\text { P-value } \\
<0.001 *\end{array}$} \\
\hline & 10.8 & - & 16.7 & & & & & & & & \\
\hline End of treatment & 8.9 & - & 15 & 11.990 & \pm & 1.458 & B-A & 0.624 & 0.895 & 4.929 & $<0.001 *$ \\
\hline \multirow[t]{3}{*}{ After 6 months } & 9.8 & - & 15 & 12.540 & \pm & 1.238 & E-A & -0.550 & 1.050 & -3.702 & $0.001^{*}$ \\
\hline & \multicolumn{6}{|c|}{ WBCs } & COMP. & \multicolumn{2}{|c|}{ Differences } & \multicolumn{2}{|c|}{ Paired Test } \\
\hline & \multicolumn{3}{|c|}{ Range } & Mean & \pm & SD & & Mean & SD & $\mathbf{T}$ & P-value \\
\hline Before treatment & 2.3 & - & 11.3 & 5.057 & \pm & 1.860 & B-E & 0.043 & 1.589 & 0.191 & 0.849 \\
\hline End of treatment & 1.9 & - & 10.5 & 5.014 & \pm & 1.936 & B-A & -0.467 & 1.778 & -1.856 & 0.069 \\
\hline \multirow{3}{*}{ After 6 months } & 2.46 & - & 9.5 & 5.524 & \pm & 1.834 & E-A & -0.510 & 1.754 & -2.055 & $0.045^{*}$ \\
\hline & \multicolumn{6}{|c|}{ Platelets } & COMP. & \multicolumn{2}{|c|}{ Differences } & \multicolumn{2}{|c|}{ Paired Test } \\
\hline & \multicolumn{3}{|c|}{ Range } & Mean & \pm & SD & & Mean & SD & $\mathbf{T}$ & P-value \\
\hline Before treatment & 52 & - & 250 & 120.660 & \pm & 44.150 & B-E & 3.380 & 21.371 & 1.118 & 0.269 \\
\hline End of treatment & 47 & - & 200 & 117.280 & \pm & 39.750 & B-A & -1.500 & 18.747 & -0.566 & 0.574 \\
\hline After 6 months & 60 & - & 250 & 122.160 & \pm & 45.295 & E-A & -4.880 & 19.191 & -1.798 & 0.078 \\
\hline & & & otal bili & irubin (m & $\mathrm{g} / \mathrm{dL}$ & & COMP. & Diff & ences & Pair & Test \\
\hline & & Lang & & Mean & \pm & SD & & Mean & SD & $\mathbf{T}$ & P-value \\
\hline Before treatment & 0.5 & - & 2.9 & 1.151 & \pm & 0.507 & B-E & -0.115 & 0.373 & -2.189 & $0.033^{*}$ \\
\hline End of treatment & 0.4 & - & 2.8 & 1.266 & \pm & 0.604 & B-A & 0.033 & 0.319 & 0.723 & 0.473 \\
\hline After 6 months & 0.4 & - & 2.8 & 1.118 & \pm & 0.519 & E-A & 0.148 & 0.270 & 3.880 & $<0.001 *$ \\
\hline & & & & $\mathbf{L T}(\mathbf{U} / \mathbf{L})$ & & & COMP. & Diffe & ences & Pair & Test \\
\hline & & ang & & Mean & \pm & SD & & Mean & SD & $\mathbf{T}$ & P-value \\
\hline Before treatment & 13 & - & 198 & 70.700 & \pm & 45.007 & B-E & 40.660 & 36.118 & 7.960 & $<0.001 *$ \\
\hline End of treatment & 6 & - & 90 & 30.040 & \pm & 16.738 & B-A & 52.280 & 44.509 & 8.306 & $<0.001 *$ \\
\hline After 6 months & 6 & - & 74 & 18.420 & \pm & 11.117 & E-A & 11.620 & 17.495 & 4.697 & $<0.001 *$ \\
\hline & & & & ST (U/L) & & & COMP. & Diffe & ences & Pair & Test \\
\hline & & ang & & Mean & \pm & SD & & Mean & SD & $\mathbf{T}$ & P-value \\
\hline Before treatment & 8 & - & 219 & 83.820 & \pm & 51.227 & B-E & 51.420 & 44.349 & 8.198 & $<0.001 *$ \\
\hline End of treatment & 8 & - & 120 & 32.400 & \pm & 19.570 & B-A & 64.200 & 51.426 & 8.828 & $<0.001 *$ \\
\hline After 6 months & 6 & - & 69 & 19.620 & \pm & 13.840 & E-A & 12.780 & 18.029 & 5.012 & $<0.001 *$ \\
\hline & & & S. albu & $\min (\mathrm{gm} /$ & (dL) & & COMP. & Diff & ences & Pair & Test \\
\hline & & Rang̨ & & Mean & \pm & SD & & Mean & SD & $\mathbf{T}$ & P-value \\
\hline Before treatment & 2.9 & - & 4.7 & 3.764 & \pm & 0.473 & B-E & 0.052 & 0.314 & 1.177 & 0.245 \\
\hline End of treatment & 2.8 & - & 4.6 & 3.712 & \pm & 0.505 & B-A & -0.192 & 0.330 & -4.114 & $<0.001 *$ \\
\hline After 6 months & 2.9 & - & 5 & 3.956 & \pm & 0.565 & E-A & -0.244 & 0.393 & -4.390 & $<0.001 *$ \\
\hline & & $\mathrm{Al}_{\mathbf{F}}$ & ha Feto & Protein & $(\mathrm{ng} / \mathrm{n}$ & $n L)$ & COMP. & Diff & ences & Pair & Test \\
\hline & & Ran & & Mean & \pm & SD & & Mean & SD & $\mathbf{T}$ & P-value \\
\hline Before treatment & 1.5 & - & 45 & 11.512 & \pm & 11.454 & B-E & 1.106 & 5.484 & 1.426 & 0.160 \\
\hline End of treatment & 1.8 & - & 39.8 & 10.406 & \pm & 8.791 & B-A & 1.953 & 5.584 & 2.473 & $0.017 *$ \\
\hline After 6 months & 1.4 & - & 40 & 9.559 & \pm & 8.692 & E-A & 0.847 & 4.662 & 1.284 & 0.205 \\
\hline
\end{tabular}




\begin{tabular}{|c|c|c|c|c|c|c|c|c|c|c|c|}
\hline \multirow[b]{3}{*}{ Beforetreatment } & \multicolumn{6}{|c|}{ MELD Score } & \multirow[t]{2}{*}{ COMP. } & \multicolumn{2}{|c|}{ Differences } & \multicolumn{2}{|c|}{ Paired Test } \\
\hline & \multicolumn{3}{|c|}{ Range } & Mean & \pm & SD & & Mean & SD & $\mathbf{T}$ & P-value \\
\hline & 6 & - & 16 & 9.040 & \pm & 2.441 & B-E & -0.320 & 1.463 & -1.547 & 0.128 \\
\hline Endof treatment & 6 & - & 15 & 9.360 & \pm & 2.617 & B-A & -0.100 & 1.821 & -0.388 & 0.699 \\
\hline After 6 months & 6 & - & 16 & 9.140 & \pm & 2.330 & E-A & 0.220 & 1.670 & 0.932 & 0.356 \\
\hline
\end{tabular}

(COMP comparing, B Before treatment, E End of treatment, A After 6 months from end of treatment. )

Table.2 All Doppler parameters follow up in our study

\begin{tabular}{|c|c|c|c|c|c|c|c|c|c|c|c|c|}
\hline \multirow{4}{*}{$\begin{array}{l}\text { Portal vein } \\
\text { flow velocity }\end{array}$} & \multirow[b]{3}{*}{ Before treatment } & \multirow{2}{*}{\multicolumn{3}{|c|}{ Range }} & \multirow{3}{*}{$\begin{array}{l}\text { Mean } \\
11.889\end{array}$} & \multirow[b]{3}{*}{ \pm} & \multirow{3}{*}{$\begin{array}{c}\text { SD } \\
3.529\end{array}$} & \multirow{3}{*}{$\begin{array}{c}\text { COMP. } \\
\text { B-E }\end{array}$} & \multicolumn{2}{|c|}{ Differences } & \multicolumn{2}{|c|}{ Paired Test } \\
\hline & & & & & & & & & \multirow{2}{*}{$\begin{array}{l}\text { Mean } \\
-1.795\end{array}$} & \multirow{2}{*}{$\begin{array}{c}\text { SD } \\
2.248\end{array}$} & \multirow{2}{*}{$\begin{array}{c}\mathbf{T} \\
-5.647\end{array}$} & \multirow{2}{*}{$\begin{array}{l}\text { P-value } \\
<0.001 *\end{array}$} \\
\hline & & 6.1 & - & 20.7 & & & & & & & & \\
\hline & End of treatment & 7 & - & 22.7 & 13.684 & \pm & 3.639 & B-A & -3.205 & 2.662 & -8.513 & $<0.001 *$ \\
\hline & After 6 months & 8.3 & - & 23.9 & 15.094 & \pm & 4.250 & E-A & -1.410 & 1.344 & -7.420 & $<0.001 *$ \\
\hline \multirow{3}{*}{$\begin{array}{c}(\mathrm{CI}) \\
\text { congestion } \\
\text { index }\end{array}$} & Before treatment & 0.054 & - & 0.468 & 0.166 & \pm & 0.090 & B-E & 0.024 & 0.035 & 4.950 & $<0.001 *$ \\
\hline & End of treatment & 0.048 & - & 0.382 & 0.142 & \pm & 0.076 & B-A & 0.037 & 0.040 & 6.427 & $<0.001^{*}$ \\
\hline & After 6 months & 0.046 & - & 0.332 & 0.130 & \pm & 0.068 & E-A & 0.012 & 0.015 & 5.711 & $<0.001^{*}$ \\
\hline \multirow{3}{*}{$\begin{array}{l}\text { Arterial } \\
\text { pulsatility } \\
\text { index }\end{array}$} & Before treatment & 1.1 & - & 2.54 & 1.669 & \pm & 0.323 & B-E & 0.103 & 0.302 & 2.410 & $0.020^{*}$ \\
\hline & End of treatment & 1.22 & - & 2.25 & 1 & \pm & 74 & & 5 & 8 & 2.635 & $0.011^{*}$ \\
\hline & After 6 months & 0.65 & - & 2.29 & 1.524 & \pm & 0.329 & E-A & 0.042 & 0.226 & 1.308 & 0.197 \\
\hline \multirow{3}{*}{$\begin{array}{c}\text { Arterial } \\
\text { resistive } \\
\text { index }\end{array}$} & Before treatment & 0.67 & - & 0.94 & 0.811 & \pm & 0.073 & B-E & 0.038 & 0.098 & 2.770 & $0.008^{*}$ \\
\hline & End of treatment & 0.65 & - & 0.97 & 0.773 & \pm & 0.068 & B-A & 0.066 & 0.107 & 4.363 & $<0.001^{*}$ \\
\hline & After 6 months & 0.6 & - & 0.9 & 0.745 & \pm & 0.073 & E-A & 0.028 & 0.055 & 3.588 & $0.001 *$ \\
\hline \multirow{3}{*}{$\begin{array}{c}\text { Liver } \\
\text { vascular } \\
\text { index(LVI) }\end{array}$} & Before treatment & 3.51 & - & 14.47 & 7.372 & \pm & 2.620 & B-E & -1.765 & 2.408 & -5.182 & $<0.001 *$ \\
\hline & End of treatment & 4.34 & - & 16.69 & 9.137 & \pm & 2.909 & B-A & -3.330 & 4.458 & -5.282 & $<0.001 *$ \\
\hline & After 6 months & 4.41 & - & 34.46 & 10.702 & \pm & 5.231 & E-A & -1.565 & 3.552 & -3.116 & $0.003^{*}$ \\
\hline
\end{tabular}

(COMP comparing, B Before treatment, E End of treatment, A After 6 months from end of treatment.)

Fig.1 Treatment regimens used in our study

(S sofosbuvir, D daclatasvir, Sim simeprevir,R ribavirin)

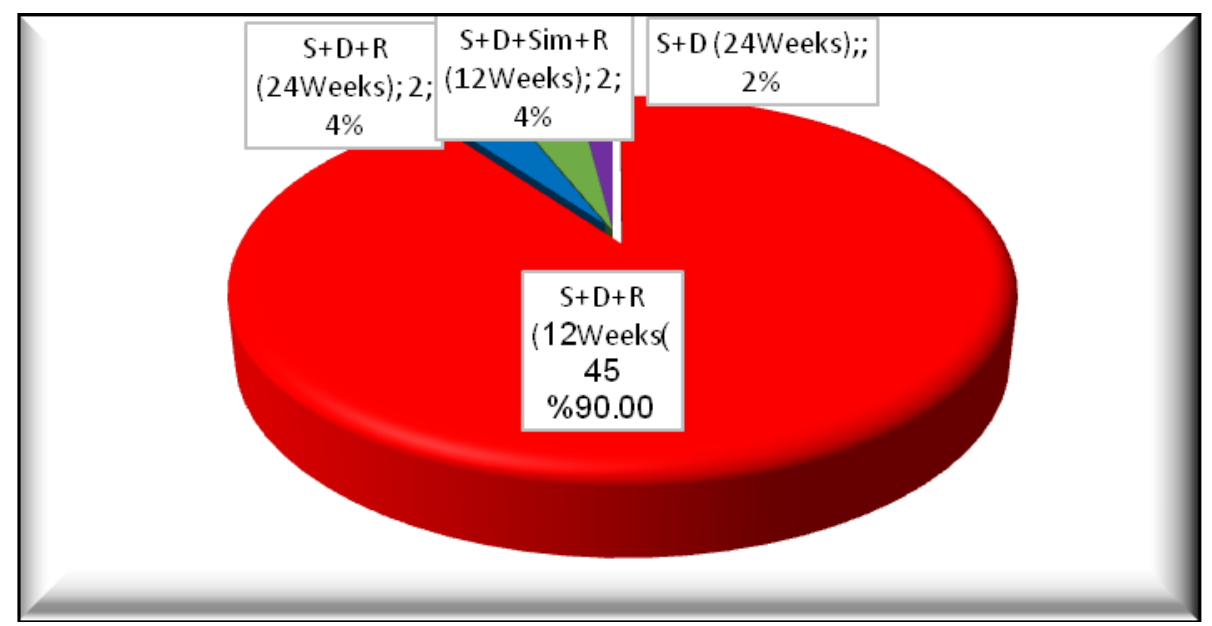


Fig.2 Doppler ultrasound picture showing PVV 6 months after the end of DAAs therapy (hepatopetal flow pattern . maximum PVV=16.8 cm/s, minimum PVV=11.3)

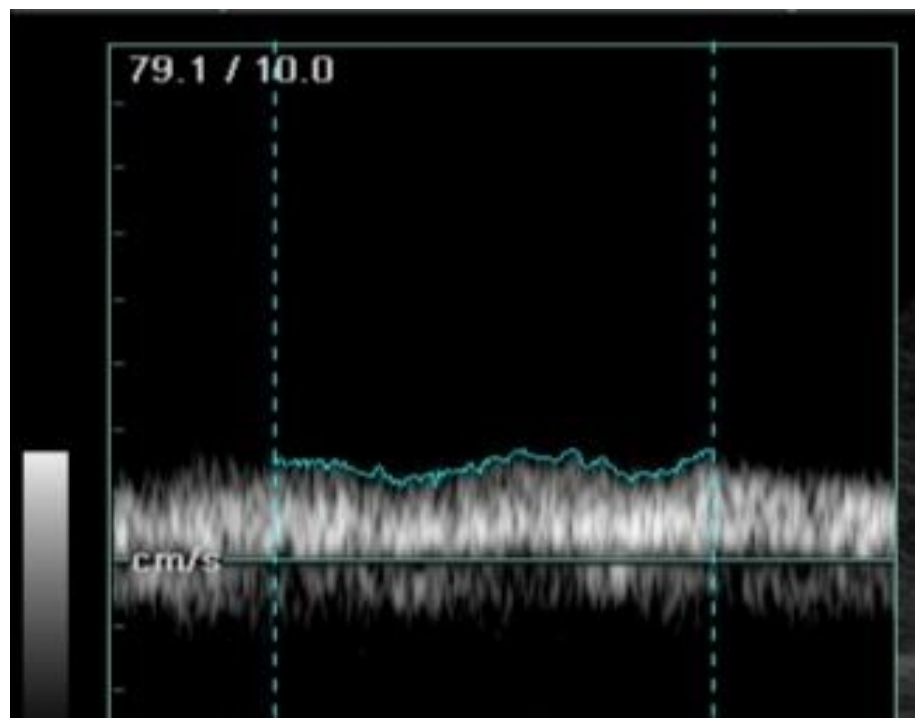

Fig.3 Doppler ultrasound picture showing HARI=0.77 and HAPI=1.72 at the end of treatment

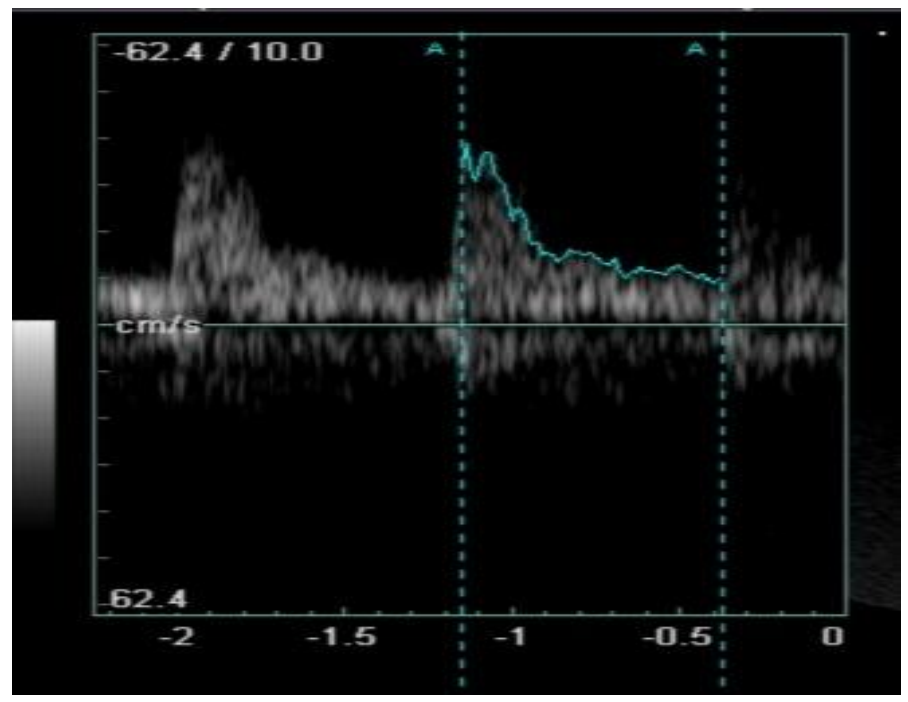

Fifty (50) patients suffering from cirrhosis post $\mathrm{HCV}$ infection were included in our study to assess their portal hemodynamic before and after treating them with direct acting antivirals (DAAs).

Forty seven (94\%) patients had achieved sustained virological response. This was in accordance with previous Egyptian studies. $(14,15)$ when we compared liver function tests in our patients before therapy with end of therapy, and before therapy with after 6 months after the end of therapy, liver enzymes (ALT and AST) in our patients showed a highly significant and sustained decrease and even normalization, while serum albumin showed a highly significant increase 6 months after end of therapy. 
On the other hand total bilirubin showed a significant increase at the end of therapy, while showed a significant decrease after 6 months of ending therapy. This increase was limited during receiving DAAs therapy and normalized after achieving SVR. That can be attributed to Ribavirin.

As regard complete blood picture hemoglobin levels showed a significant decreased at end of therapy, these levels were significantly improved 6 months after the end of therapy. While WBCs showed a significant increase 6 months after the end of therapy.

On the other hand, model for end-stage liver disease score (MELD) and Child-TurcottePugh score (CTP) showed no significant difference in our study population.

These results were in agreement with Elsharkawy et al., 2017 who studied the effect of DAAs on liver biochemical profile and haematological indices during and after treatment, and they added that the drop in Hemoglobin and platelets in cirrhotic patients were noted with SOF/RBV, while SOF/SIM showed rise in bilirubin. (16)

In accordance to our results, Deterding et al., 2015 showed that DAAs treatment for hepatitis $\mathrm{C}$ patients with advanced liver cirrhosis restores liver function, and may thereby reduce the need for liver transplantations.(17)

In addition, Mohamed, et al., 2017 concluded that liver function parameters, serum albumin, bilirubin, platelet count, and international normalized ratio improved significantly in the majority of patients who achieved sustained virological response, in the contrary to our results, Mohamed, et al., 2017 documented a reduction in the model for end-stage liver disease score (MELD) and an improvement in Child-Turcotte-Pugh score (CTP) in 44 of their studied patients. This might be due to different characters in our study population as 92\% (46) of our patients were CTP class A while $8 \%$ (4) patients were CTP class B, and just $6 \%$ of patients had ascites of mild to moderate degree.(18)

There was a significant decrease in the level of alpha feto protein 6 months after the end of therapy when compared with that before treatment. This finding was in agreement with Nguyen et al., 2017. (19) This may be due to suppressing viral replication,(20-24) also reduced liver inflammation in patients achieved SVR may be linked to reduced alpha feto protein. $(23,25)$

There was a controversy as regard portal vein diameter and its relation to portal hypertension as Hagen-Ansert, 2006 had reported that a diameter greater than $13 \mathrm{~mm}$ is considered as a predictor of portal hypertension in patients with cirrhosis.(26) In contrast, Jaheen (2003) found that PV dilatation is a specific but insensitive indicator of portal hypertension as they noted that this sign may also occur in the absence of portal hypertension (e.g. in response to massive splenomegaly or acute PV thrombosis).(27)

As regard hemodynamic changes; There was a highly significant increase in Portal vein flow velocity and liver vascular index (LVI) while congestion index and hepatic artery resistive index were significantly decreased at end of therapy and at 6 months after end of therapy that can be attributed to resolution of necro -inflammation, consequently improvement of fibrosis and decreased intrahepatic vascular resistance after achieving SVR due to the impairment of intrahepatic nitric oxide (NO) and the pharmacological alteration of stellate cell activity.(28) 
Similar to our results, Puente et al., 2017 who measured the effect of interferon based regimen on HVPG and liver stiffness measured by Fibroscan in $16 \mathrm{HCV}$ patients before, 8 weeks and 24 weeks post achieving SVR and concluded that there was a significant reduction in HVPG and liver stiffness in more than half and one-third of patients achieving SVR.(29)

In another study $24 \%$ of 33 cirrhotic patients received sofosbuvir + ribavirin for 48 weeks achieved $a \geq 20 \%$ decrease in HVPG at the end of treatment, though they concluded that this was moderate change, they also found that $69 \%$ of patients had improvement in their Child-Pugh class from B to A.(30)

One of the limitations of our study is small sample size; also an extended follow up of these patients is needed. So, large-scale, longterm clinical studies using non invasive tools to assess the long-term effect of DAAs on portal hemodynamics.

In conclusion, achieving Sustained virologic response by the use of direct-acting antivirals in HCV related cirrhosis, improve liver blood flow and liver perfusion.

\section{Acknowledgement}

This study couldn't be accomplished without the support of the National Committee for Control of Viral Hepatitis, Ministry of Health and population, Egypt.

\section{References}

1. Pawlotsky JM: Hepatitis $\mathrm{C}$ virus resistance to direct-acting antiviral drugs in interferon free regimens. Gastroenterol 2016; 151(1):70-86.

2. Stanaway J, Flaxman A, Naghavi M, et al., The global burden of viral hepatitis from 1990 to 2013: findings from the Global Burden of Disease Study 2013. Lancet2016; 388 (10049): 1081-1088.
3. Veldt BJ, Heathcote EJ, Wedemeyer H, et al., Sustained virologic response and clinical outcomes in patients with chronic hepatitis C and advanced fibrosis. Ann Intern Med. 2007. 147(10):677-684.

4. Poynard T, McHutchison J, Manns M, et al., Impact of pegylated interferon alfa- $2 b$ and ribavirin on liver fibrosis in patients with chronic hepatitis C. Gastroenterology.2002;122(5):1303-1313.

5. Poordad F and Dieterich D: Treating hepatitis $\mathrm{C}$ : current standard of care and emerging direct-acting antiviral agents. J Viral Hepat 2012. Jul; 19(7):449-64.

6. García-Pagán J, Gracia-Sancho J and Bosch J: Functional aspects on the pathophysiology of portal hypertension in cirrhosis Journal of Hepatology 2012, vol. (57), 458-461.

7. Kumar A, Sharma P and Sarin SK: Hepatic venous pressure gradient measurement. Indian J Gastroentemrol 2008; 25 (3): 74-80.

8. Singal AK, Ahmad M, Soloway RD: Duplex Doppler ultrasound examination of the portal venous system: an emerging novel technique for the estimation of portal vein pressure. Dig Dis Sci 2009. ;55:1230-1240.

9. Simonovsky V: The diagnosis of cirrhosis by high resolution ultrasound of the liver surface. Br J Radiol 1999; 72:29-34.

10. Schuppan D and Afdhal NH: Liver cirrhosis. Lancet 2008; 371 (9615): 838-851.

11. Scheinfeld M, Bilali A, and Koenigsberg M: Understanding the spectral Doppler wave form of the hepatic veins in health and disease. Radiographics 2009; 29 (7): 20812098.

12. Haktanir A., Cihan B.S and Çelenk C.S: Value of Doppler sonography in assessing the progression of chronic viral hepatitis and in the diagnosis and Grading of Cirrhosis. J Ultrasound Med 2005; 24:311321

13. Simmons B, Saleem J, Heath K, et al., LongTerm Treatment Outcomes of Patients Infected With Hepatitis C Virus: A Systematic Review and Meta-analysis of the Survival Benefit of Achieving a Sustained Virological Response. Clin Infect Dis 2015; 61: 730-740.

14. Shiha G, Soliman R, ElBasiony M, et al., Sofosbuvir plus Daclatasvir with or without ribavirin for treatment of chronic $\mathrm{HCV}$ 
genotype 4 patients: real-life experience. Hepatol Int 2018. Jul; 12(4):339-347.

15. Abd-Elsalam, Sharaf-Eldin. M, Soliman. S,et al., Efficacy and safety of sofosbuvir plus ribavirin for treatment of cirrhotic patients with genotype 4 hepatitis $\mathrm{C}$ virus in real-life clinical practice, Archives of Virology 2017, pp. 1-6.

16. Elsharkawy A, Eletreby R, Fouad R, et al., Impact of different sofosbuvir based treatment regimens on the biochemical profile of chronic hepatitis $\mathrm{C}$ genotype 4 patients. Expert Rev Gastroenterol Hepatol 2017. Aug; 11(8):773-778.

17. Deterding, K., Höner zu Siederdissen, C., Port, K., et al., Improvement of liver function parameters in advanced $\mathrm{HCV}$ - associated liver cirrhosis by IFN- free antiviral therapies. Aliment Pharmacol Ther 2015, 42: 889-901.

18. Mohamed MS, Hanafy AS and Bassiony MAA: Sofosbuvir and daclatasvir plus ribavirin treatment improve liver function parameters and clinical outcomes in Egyptian chronic hepatitis C patients. Eur $J$ Gastroenterol Hepatol 2017. Dec; 29(12):1368-1372.

19. Nguyen K, Jimenez M, Moghadam N, et al., Decrease of Alpha-fetoprotein in Patients with Cirrhosis Treated with Direct-acting Antivirals.J Clin Transl Hepatol 2017; 5(1):43-49.

20. Arase Y, Ikeda K, Suzuki F, et al., Prolongedinterferon therapy reduces hepatocarcinogenesis in aged-patients with chronic hepatitis C. J Med Virol 2007; 79: 1095-1102.

21. Asahina Y, Tsuchiya K, Nishimura T, et al., afetoprotein levels after interferon therapy and risk of hepatocarcinogenesis in chronic hepatitis C. Hepatology 2013;58:1253-1262.

22. Tachi Y, Hirai T, Ishizu Y, et al., a-fetoprotein levels after interferon therapy predict regression of liver fibrosis in patients with sustained virological response. $J$ Gastroenterol Hepatol 2016; 31: 1001-1008.

23. Yamada R, Hiramatsu N, Oze T, et al., Impact of alpha-fetoprotein on hepatocellular carcinoma development during entecavir treatment of chronic hepatitis B virus infection. J Gastroenterol 2015; 50: 785-794.

24. El Raziky M, Attia D, El Akel W, et al., Hepatic fibrosis and serum alpha-fetoprotein (AFP) as predictors of response to $\mathrm{HCV}$ treatment and factors associated with serum AFP normalisation after treatment. Arab $J$ Gastroenterol 2013;14:94-98.

25. Kim GA, Seock CH, Park JW, et al., Reappraisal of serum alpha-foetoprotein as a surveillance test for hepatocellular carcinoma during entecavir treatment. Liver Int 2015; 35 : 232-239.

26. Hagen-Ansert SL. 2006: Textbook of diagnostic ultrasonography. 6th ed. St. Louis, MO: Elsevier Mosby; 2: 1-6.

27. Jaheen A: Prevalence of portal hypertensive gastropathy and its predictive factors. Gut Review, 2003; 3: 24-33.

28. Ballet F, Chretien Y, Rey C, et al., Differential response of normal and cirrhotic liver to vasoactive agents. A study in the isolated perfused rat liver. J Pharmacol Exp Ther 1988; 244: 283-9.

29. Puente Á, Cabezas J, López Arias MJ, et al., Influence of sustained viral response on the regression of fibrosis and portal hypertension in cirrhotic HCV patients treated with antiviral triple therapy. Rev Esp Enferm Dig 2017; 109: $17-25$

30. Afdhal N, Everson GT, Calleja JL, et al., LP13: Effect of long term viral suppression with sofosbuvir + ribavirin on hepatic venous pressure gradient in $\mathrm{HCV}$ infected patients with cirrhosis and portal hypertension. $J$ Hepatol 2015; 62 (Supp 2): S269-S270.

\section{How to cite this article:}

Amira Shaaban Soliman, Fathia El sayed Asal, Sahar Abdel Tawab El Yamani, Amr Mohamed Tawfik Elbadry, Nehad Ibrahim Hawash and Mahmoud Anees Khedr. 2020. The Effect of Direct Acting Antivirals on Portal Hemodynamics in Patients with Post Hepatitis C Cirrhosis: Doppler Study. Int.J.Curr.Microbiol.App.Sci. 9(10): 3705-3714. doi: https://doi.org/10.20546/ijcmas.2020.910.427 